\title{
Attenuation of water flow inside seagrass canopies of differing structure
}

\author{
Charles H. Peterson ${ }^{1, *}$, Richard A. Luettich $\mathrm{Jr}^{1}{ }$, Fiorenza Micheli ${ }^{1,2}$, \\ Gregory A. Skilleter ${ }^{1,3}$
}

${ }^{1}$ University of North Carolina at Chapel Hill, Institute of Marine Sciences, Morehead City, North Carolina 28557, USA

${ }^{2}$ Present address: Hopkins Marine Station, Stanford University, Pacific Grove, California 93950, USA

${ }^{3}$ Present address: Zoology Department, University of Queensland, St. Lucia, Queensland 4067, Australia

\begin{abstract}
An understanding of how habitat structure influences physical environmental processes that are important to organisms utilizing the habitat is a necessary basis for predicting biological responses to habitat variation. Seagrass meadows represent an important coastal nursery habitat that modifies the local flow environment. We used basic fluid-dynamic balances to construct a simple model of the effects of seagrass habitat structure on mean flow within and above the canopy, and tested quantitative predictions of the model against published flume observations and our own field measurements. In the field, flow reduction was detected in 10 of 13 cases inside the canopies of 5 seagrass beds varying in vegetation density (11 to $52 \mathrm{~m}^{2} \mathrm{~m}^{-3}$ ) and upstream flow (5 to $14 \mathrm{~cm} \mathrm{~s}^{-1}$ ). The field data demonstrated greater flow reductions inside the canopy with increasing vegetation density. Flume data further confirmed a quantitative prediction of our model that the vertically integrated flow velocity inside the canopy would vary inversely with the square root of vegetation density. The model also predicted that the width of the 'seagrass-edge zone', in which flow decelerates, is a declining function of vegetation density, indicating that 'edge effects' (and by inference variation among patches of differing sizes) change predictably with seagrass bed structure. Empirical observations and simplified theory relating mean flow reduction to seagrass vegetation density can now be used to generate predictions of dependent biological responses such as variation in gamete fertilization, larval and spore settlement, and growth rates of organisms responsive to fluxes.
\end{abstract}

KEY WORDS: Flow-establishment zone · Habitat structure ' Hydrodynamics · Seagrass · Sub-canopy $\cdot$ Velocity reduction $\cdot$ Vegetation density

\section{INTRODUCTION}

An understanding of the physical environmental processes that are important to ecosystem functions, such as water flow in marine habitats, provides a framework for evaluating biological patterns and even for making a priori predictions of biological responses to environmental forcing (e.g. Butman 1987, Vogel 1994). Emergent biogenic structures interact with and modify water flow in biologically important benthic habitats in ways that depend largely on the habitat structure. Seagrasses represent one such important structural habitat by providing vegetation projecting above the surface of what can be otherwise a relatively flat sedimentary bottom. Seagrasses differ among and within species in the morphology of their emergent leaves, which vary in shape, blade dimensions and other architectural features (McRoy \& McMillan 1977, Schutten \& Davy 2000). On a coarser scale, the 3dimensional spatial arrangement of the emergent shoots and leaves can differ, with vegetation density being perhaps the most critical variable (Fonseca et al. 1982, Gambi et al. 1990, Verduin \& Backhaus 2000, Abdelrhman 2003). Substantial differences in sizes of habitat patches also occur (Fonseca \& Bell 1998). Finally, on a landscape scale, the spatial configuration of patches of seagrass and other aquatic habitats such as salt marshes, mangroves, oyster reefs, and sandflats 
differs among sites, with probable consequences for biological functions (Irlandi \& Crawford 1997, but see Hovel et al. 2002).

The projection of physical structures in the form of seagrass shoots and leaves into the water column is known to have an impact on the hydrodynamics of water flow near the seafloor for both unidirectional (e.g. tidally driven) flows (Gambi et al. 1990, Ackerman \& Okubo 1993, Worcester 1995, Kutija \& Hong 1996, Koch \& Gust 1999, Nepf \& Koch 1999, Abdelrhman 2003) and oscillatory, wave-dominated flows (Koch 1996, Koch \& Gust 1999, Verduin \& Backhaus 2000). Flow velocities inside the seagrass canopy are reduced by the frictional effects of the vegetation (Fonseca et al. 1982, Gambi et al. 1990, Ackerman \& Okubo 1993, Koch \& Gust 1999, Verduin \& Backhaus 2000, Abdelrhman 2003). This effect of flow reduction or 'baffling' by the emergent structure of the plants is of tremendous significance to many ecosystem functions. Reduction of flow inside seagrass canopies causes (1) deposition and retention of finer sediments (Ginsburg \& Lowenstam 1958, Scoffin 1970), to which benthic invertebrates are sensitive; (2) enhanced deposition of planktonic larvae of invertebrates at the canopy margins and potential depletion within the beds (Eckman 1987); (3) greater trapping of drifting macroalgae (Bell et al. 1995); (4) a modified nutritional environment for suspension-feeding animals (Muschenheim 1987, Fréchette et al. 1989, Irlandi \& Peterson 1991) and for the seagrasses themselves (Koch 1994); (5) greater stability of the plants (Schutten \& Davy 2000); (6) low-flow conditions in which feeding opportunities for predators and their consequent impacts can be substantially altered (e.g. Palmer 1988).

To advance our understanding of the effects of structural variation in seagrass habitats, we used basic fluiddynamic balances to develop a simplified model to predict (1) the alteration in the vertically integrated flow inside and above a vegetated canopy, and (2) the width of the flow-establishment zone at the lateral edge of the canopy (i.e. the zone in which the velocity profile is modified as the water-flow decelerates rapidly from its velocity outside the canopy to a lower velocity within the canopy). We then tested the predictions of the model by reanalyzing published quantitative results from a laboratory flume study (Gambi et al. 1990) and by mensurative field observations of the attenuation of unidirectional flow in seagrass beds of differing structure. We focused on these particular response variables because the magnitude of flow reduction inside canopies is extremely sensitive to vegetation structure, and because anthropogenic habitat fragmentation (Thayer et al. 1975, Ruckelshaus \& Hays 1998) and restoration efforts in seagrass beds (Thayer 1992) can greatly alter the extent of the edge habitat.

\section{MODEL}

Model background. Past studies of the effects of physical structures projecting into a moving fluid include analyses of air flow through forests and crop canopies as well as water flow through various types of aquatic vegetation. The atmospheric studies (reviewed by Raupach \& Thom 1981 and Raupach et al. 1991) have included experimental studies in wind tunnels, extensive field observations, and sophisticated modeling.

In the atmosphere (a fluid which typically has a large depth relative to canopy height), air flow well above the canopy follows the standard boundary-layer theory, in which mean velocity under neutrally stable conditions can be described by a logarithmic profile. (This involves averaging over a sufficient time scale to eliminate turbulent fluctuations and over a sufficient spatial scale to eliminate variability arising from individual canopy elements.) In this above-canopy region of air flow, the canopy represents a collection of roughness elements acting upon the mean flow and causing displacement (some distance above the ground) of the projected zero point of the mean velocity profile. Turbulence is primarily generated by shear in the mean flow. Inside the canopy, considerable shear occurs in a region near the top. Turbulence here is generated by shear in the mean flow, by eddies around canopy elements, and by movements of supple canopy elements. Presumably, the more rigid the canopy elements (e.g. trees), the greater the shear contribution by eddies around them, and the more supple the canopy elements (e.g. the crops), the lower the shear. Further inside the canopy, the velocity profile becomes increasingly uniform with decreasing distance from the ground, except close to the ground, where a region of velocity shear develops in response to the frictional properties of the ground. Turbulence inside the canopy is generated primarily by eddies around canopy structures, such as branches and leaves.

The results of studies on the effects of aquatic vegetation on water flows are generally consistent with those of atmospheric studies. A detailed flume study by Gambi et al. (1990) and modeling studies by Lopez \& Garcia (1997) and Abdelrhman (2003) reported logarithmic velocity profiles above canopies. Usually, however, the typically shallow (but see Grizzle et al. 1996 and Verduin \& Backhaus 2000) water depths overlying canopies of marine vegetation, enhanced turbulence, movement of flexible canopy elements, and interactions with the sea-surface boundary have rendered detection of overlying logarithmic profiles difficult in the field. As observed in atmospheric studies, the region near the canopy top of aquatic vegetation is one of high shear and turbulence (Burke \& Stolzenbach 1983, 
Gambi et al. 1990). Aquatic turbulence is, at least partially, associated with movement of flexible canopy elements (Ackerman \& Okubo 1993, Grizzle et al. 1996, Verduin \& Backhaus 2000). As in air, the velocity profile inside the canopy becomes increasingly uniform with decreasing distance to the ground, until the frictional influence of the sea bottom becomes effective. Velocity fluctuations inside the canopy are primarily due to eddies around the various canopy structures (Anderson \& Charters 1982, Burke \& Stolzenbach 1983, Leonard \& Luther 1995) and, in relatively supple canopies, from movement of the canopy itself (Gambi et al. 1990, Ackerman \& Okubo 1993, Verduin \& Backhaus 2000). Drag on canopy structures causes loss of momentum in the mean flow; thus downstream flow is slower than flow upstream of the canopy (Kutija \& Hong 1996, Verduin \& Backhaus 2000). Near the upstream edge of a canopy, an increase in mean flow-velocity over the top of a canopy has also frequently been noted (Fonseca et al. 1982, Gambi et al. 1990, Worcester 1995, Koch 1996, Koch \& Gust 1999, Verduin \& Backhaus 2000, Abdelrhman 2003). Beginning at the upstream edge, there is a flow-establishment zone inside the canopy, in which velocity changes, with the flow decelerating rapidly from ambient velocity (i.e. outside the canopy) to a lower velocity within the canopy.

Previous models have described various aspects of air flow through terrestrial vegetation (e.g. see reviews by Raupach \& Thom 1981 and Raupach et al. 1991), water flow through various vegetated canopies (Reid \& Whitaker 1976, Burke \& Stolzenbach 1983, Kutija \& Hong 1996, Lopez \& Garcia 1997) and, recently, water flow in seagrass beds (Verduin \& Backhaus 2000, Abdelrhman 2003). Verduin \& Backhaus (2000) developed a 3-dimensional, numerical model, including plant-flow interaction, of water flow through Amphibolis antartica beds under conditions of swell (wave)forcing. By providing different friction factors for architecturally varying components of the plants, water flow was shown to be altered by the morphology of the plant canopy. The computational results agreed reasonably with observed in situ velocity and kinetic energy changes in a seagrass bed subject to incident surface waves. Abdelrhman (2003) based his seagrass model on velocity profiles commonly used in air-canopy studies. He assumed a velocity profile that is exponential with height below the canopy and logarithmic with height above the canopy. The parameters required for this model are canopy-friction velocity, canopy-roughness height, canopy-displacement height, canopy-mixing length, and canopy-drag coefficient. Canopy-friction velocity is obtained by balancing total water flow per unit width through and above the canopy with that upstream of the canopy. Canopy-roughness height, displacement height, and mixing length are assumed to depend on the physical structure of the canopy (vegetation density and canopy height) and a proportionality coefficient. The canopydrag coefficient and the proportionality coefficient can be calculated based on other data, or selected to best fit the model to available data. Abdelrhman (2003) successfully calibrated this model to detailed velocity profiles measured in a flume study by Gambi et al. (1990) that included multiple incident-flow speeds and within-canopy seagrass densities. The final calibrations used a constant canopy-drag coefficient (0.7) and tuned the proportionality coefficient for the different flow speeds and canopy configurations.

Model derivation. Our aim was to develop a quantitative model specifying the bulk (i.e. vertically averaged) flow reduction inside a seagrass canopy, the flow enhancement above a seagrass canopy, and the width of the outer zone of the canopy that is required for the flow to decelerate from ambient velocity to a lower within-canopy velocity. While vertically averaged flow reduction can be derived from Abdelrhman's (2003) model, our approach has a very different underlying basis (a simple momentum balance) and depends on estimating a single parameter, the canopy-drag coefficient. Our model also predicts the width of the flowestablishment zone. Thus, the new model can provide important insights into the fundamental physical processes governing water flow through seagrass beds, and complements the vertically explicit model of Abdelrhman (2003). The simplification intrinsic to our model is appropriate for many biological applications.

Burke \& Stolzenbach (1983) found that for flows driven by a free-surface slope (e.g. tides) at typical marshgrass densities, a momentum balance is maintained between the free surface-slope and drag on the canopy elements. Assuming a standard quadratic drag and a coordinate system with $x$ aligned with the mean flow direction and $z$ aligned with the vertical, then

$$
-g \frac{\mathrm{d} \eta}{\mathrm{d} x} \approx a C_{\mathrm{e}} u^{2}
$$

where $g$ is the acceleration of gravity, $\eta$ is the free surface-elevation, $C_{\mathrm{e}}$ is a canopy drag coefficient, $a(z)$ is the vegetation density (area of obstructions per unit volume of water) and $u(z)$ is the mean flow-velocity. The canopy-drag coefficient will depend on the shape of the canopy elements (i.e. cylindrical stalks will have a different value from flat, sheet-like blades) and their flexibility and orientation in the flow, which cause differences in the quantitative flow-response within beds of similar vegetation density but with different structural architectures (e.g. Schutten \& Davy 2000). Given our present limited knowledge of the drag of seagrass canopies, we presume that the drag coefficient would need to be determined as a fitting parameter. 
Since the free-surface slope in Eq. (1) is not a function of $z_{1}$ if vegetation density and the canopy-drag coefficient are constant with $z$, velocity will also not change with depth inside the canopy. Alternatively, velocity should vary inversely with vegetation density (or drag coefficient) as it (they) change(s) with depth. These predictions correspond well with field observations of Burke \& Stolzenbach (1983), Jackson \& Winant (1983), Ackerman \& Okubo (1993), Leonard \& Luther (1995) and Verduin \& Backhaus (2000).

Assuming shallow water-depths and a unidirectional flow, a similar balance would exist upstream of the vegetated habitat between the free surface gradient and bottom friction:

$$
-g \frac{\mathrm{d} \eta}{\mathrm{d} x} \approx C_{\mathrm{d}} U_{\mathrm{o}}^{2} / H
$$

where $C_{\mathrm{d}}$ is a bottom drag coefficient, $H$ is the mean water depth, and $U_{\mathrm{o}}$ is the depth-averaged, ambient, mean flow-velocity. If there is no significant change in the free surface-slope (e.g. a hydraulic jump does not occur, such as that recorded in a flume study by Fonseca et al. 1982), Eqs. (1) and (2) can be equated, yielding an expression for the proportional flow reduction at a particular depth inside the canopy:

$$
u / U_{\mathrm{o}} \approx\left(C_{\mathrm{d}} / H_{a} C_{\mathrm{e}}\right)^{1 / 2}
$$

Integrating Eq. (3) through the canopy yields the average flow reduction inside the canopy:

$$
U_{\mathrm{c}} / U_{\mathrm{o}} \approx \frac{1}{h} \int_{0}^{h}\left(C_{\mathrm{d}} / H_{a} C_{\mathrm{e}}\right)^{1 / 2} \mathrm{~d} z
$$

where $h$ is the height of the canopy and $U_{\mathrm{c}}$ is the vertically averaged velocity inside the canopy. If $C_{\mathrm{e}}$ and a are constant with elevation in the canopy, Eq. (4) can be further simplified to

$$
U_{\mathrm{c}} / U_{\mathrm{o}} \approx\left(C_{\mathrm{d}} / H a C_{\mathrm{e}}\right)^{1 / 2}
$$

Requiring the sum of the flux per unit width over and through the canopy to equal the flux per unit width upstream of the canopy allows a companion expression for the flow over the canopy:

$$
U_{\text {over }} / U_{\mathrm{o}} \approx 1+\frac{h}{H-h}\left[1-\left(C_{\mathrm{d}} / H a C_{\mathrm{e}}\right)^{1 / 2}\right]
$$

where $U_{\text {over }}$ is the vertically averaged velocity over the canopy. Note that the force balance used to obtain Eq. (1) is not valid in the high shear regions near the seafloor and near the canopy top. Therefore, Eqs. (3) to (6) will be most accurate when the canopy is relatively high compared to the thickness of these regions. Eq. (1) is also not valid when vegetation density approaches zero, since in that case bottom-drag beneath the canopy and vertical momentum exchange with the overlying water must also be included in the momentum balance.
An estimate can also be made of the width of the flow-establishment zone near the upstream edge of the canopy, where water flow decelerates rapidly from ambient velocity to a lower velocity within the canopy. In this region, the advective and canopy-drag terms balance (Jackson \& Winant 1983):

$$
-u \frac{\mathrm{d} u}{\mathrm{~d} x} \approx a C_{\mathrm{e}} u^{2}
$$

Assuming $C_{\mathrm{e}}$ to be independent of horizontal position, Eq. (7) can be integrated:

$$
u / u_{\mathrm{o}} \approx \exp \left(-a C_{\mathrm{e}} x\right)
$$

where $u_{0}(z)$ is the velocity upstream of the canopy. Away from the immediate vicinity of the bed where the velocity profile varies rapidly with $z$ (and Eq. [1] does not apply), we expect that $u_{0}(z) \approx U_{0}$. Combining Eqs. (3) and (8) then yields an approximation of the width of the flow-establishment zone, $x_{\text {est }}$ :

$$
x_{\mathrm{est}} \approx\left(-1 / 2 a C_{\mathrm{e}}\right) \ln \left(C_{\mathrm{d}} / a H C_{\mathrm{e}}\right)
$$

Eqs. (5), (6) and (9) provide model equations for the aspects of interest in the present study.

\section{METHODS}

To test how the density of emergent seagrass vegetation (defined as the cross-sectional surface area per unit water volume inside the canopy, and comprised of shoot density, width, and length [defined as sheath plus leaf length]) quantitatively modifies near-bottom current flows, we conducted a mensurative physical experiment. During falling tides and with wind speeds less than $\sim 5 \mathrm{~m} \mathrm{~s}^{-1}$, we measured the vertical profile of current velocities in the flow $1 \mathrm{~m}$ in front of the leading margin of seagrass beds and at 3 positions within the beds $(0.25,1.0$, and $2.0 \mathrm{~m}$ inside the edge), for each of 5 seagrass beds differing in structural parameters. The single most critical parameter, vegetation density, varied by a factor of 5 (see Table 1). The sediment surface in both the unvegetated $1 \mathrm{~m}$ fronting the seagrass beds and inside the beds was relatively smooth, ripple-free, and free of worm tubes or any other feature that would enhance bed roughness. Given the uniform bottom and inferred constancy of the sea-surface slope over the short $(3 \mathrm{~m})$ distance used for the measurements, we made the reasonable assumption that any contribution of the sediment surface to flow attenuation was constant along our transects. The 5 beds chosen for testing were (1) an eelgrass Zostera marina bed with high (3410 $\mathrm{m}^{-2}$ ) shoot density and $14 \mathrm{~cm}$ long (on average) maximal blade lengths in fall 1992; (2) the same eelgrass bed in spring 1993, when blade lengths had increased to $17 \mathrm{~cm}$ but shoot density had declined by 
$84 \%$ to $544 \mathrm{~m}^{-2}$; (3) a shoalgrass Halodule wrightii bed in fall 1994, with high $\left(3540 \mathrm{~m}^{-2}\right)$ shoot density but intermediate $(12 \mathrm{~cm})$ blade lengths; (4) a shoalgrass bed in autumn 1992, with high $\left(3740 \mathrm{~m}^{-2}\right)$ shoot density but short $(8 \mathrm{~cm})$ blade lengths; $(5)$ a shoalgrass bed in spring 1993, with both low $\left(2230 \mathrm{~m}^{-2}\right)$ shoot density and short $(7 \mathrm{~cm})$ blade lengths. Eelgrass and shoalgrass differ somewhat in rigidity, with eelgrass being more rigid. Differential flexibility can be incorporated into our simplified hydrodynamic model via its effects on the canopy-drag coefficient. At present we do not have the data necessary to specify a species- or morphology-specific drag coefficient. This shortcoming probably accounts for some unexplained variation. The lower portion of the emergent shoot representing the sheath is more rigid than the leaves that emerge from the sheath; there was no obvious large difference between species or season in the proportion of the shoot comprised of sheath, although we made no actual measurements, since our model does not incorporate such structural variation. Under the relatively slow flows studied (free-stream flows of 5 to $14 \mathrm{~cm} \mathrm{~s}^{-1}$ ), no synchronous waving of blade ends (Ackerman \& Okubo 1993, Grizzle et al. 1996) occurred during flow measurement. Epiphyte loads were minimal in each of the beds tested, so we made no attempt to quantify them or evaluate their contribution to flow modification (done only by Koch 1996). Each seagrass bed was located within and around 'Middle Marshes' and the 'Rachel Carson National Estuarine Research Reserve' in Back Sound, North Carolina, USA (see map in Irlandi \& Peterson 1991).

In each seagrass bed, the sampling regime and methods were identical. We used a Marsh-McBirney Model 201D electromagnetic current meter to measure flow-velocity at each of 5 elevations $(2,4,6,8$, and $10 \mathrm{~cm}$ ) off the seafloor at every sampling site. Because of the bending of seagrass shoots with the water flow, the actual height of the seagrass canopy was less than $10 \mathrm{~cm}$ in each bed, so that the $10 \mathrm{~cm}$ profile was always sufficient to sample the vertical extent of the canopy plus the area immediately above. The sensors of this current meter are embedded in a round head (diameter $3.77 \mathrm{~cm}$ ), the center of which was positioned at the proscribed elevation for each measurement. For each seagrass bed, we measured flow velocities along 3 replicate transects into the bed, spaced about $10 \mathrm{~m}$ apart and oriented along the flow stream and perpendicular to the edge of the bed. While the velocity profile was being measured sequentially at each site within the seagrass bed $(0.25$, 1 , and $2 \mathrm{~m}$ from the edge), a simultaneous velocity profile was measured at a reference station on the same transect but $1 \mathrm{~m}$ outside the bed. This paired design was adopted to allow independent estimates of the magnitude of flow reduction for each distance within the bed and to enable us to adjust continuously for any changes in tidal current during measurements on a given transect. Measurements began soon after an ebb flow was established. We chose ebb flows because, in this lagoonal system, ebb and flood tides are asymmetrical such that there is a slower rate of change in flow-velocity on ebb tides (Peterson et al. 1984), allowing longer periods of time for observation with minimal change in flow conditions. This introduces no bias to the data on flow reduction in response to vegetation density; it merely improves our ability to document responses. To profile the flow, we used a calibrated steel pole to position the sensor of the current meter. A flow record was then made for each elevation by averaging 3 readings taken $30 \mathrm{~s}$ apart, with an integration time constant of $6 \mathrm{~s}$. In order to establish a reference station for each transect that would experience minimal hydrodynamic influence of secondary flows induced by interactions of the flow with the seagrass bed itself, we positioned the outer site $1 \mathrm{~m}$ from the leading edge of the bed. Because seagrass beds tend to induce sediment deposition and retention, the bottom elevation often sloped upwards over the $1 \mathrm{~m}$ distance leading up to the bed, so we recorded the water depths during profiling as a means of measuring the height of such ramps.

During each period of flow-profiling, we also took several measurements of habitat structure in order to test the physical model. We estimated the average shoot density and maximal blade length (sheath length plus length of the longest leaf in each shoot) of each seagrass species at each sampling site on each transect from 3 replicate core samples $(10 \mathrm{~cm}$ diameter, $15 \mathrm{~cm}$ deep), taken at all locations where current profiles had been measured. Average maximal length was estimated from the 5 longest blades, because insertion of the core sampler cut off some leaves, biasing downwards any estimate of blade length based upon the entire sample. Blade width was measured on a sample from each species in each seagrass bed. In addition, the average height of the seagrass canopy above the seafloor was estimated for each bed with a calibrated measuring pole. From these measurements, the average cross-sectional surface area of vegetation per unit area and per unit volume of water under the canopy could be computed for use in the hydrodynamic model.

Our use of paired measurements along fixed flow paths permitted applications of ANOVA on proportionate reductions in flow velocity to assess whether any seagrass-induced reduction in flow varied with distance into each seagrass bed. To remove the effects of flow acceleration or deceleration due to changes in the total water depth between positions inside and outside a seagrass bed, we 'ramp-adjusted' each velocity ob- 
served inside a bed by the ratio total water depth at that position and measurement time:total water depth at the reference station outside the bed at the same time (Fonseca et al. 1983). Separate 1-factor ANOVAs ( $\alpha=0.05$ ) were used to analyze these adjusted velocity reductions for each elevation of each seagrass bed. Elevations are not independent, so these analytic results do not represent separate independent estimates of flow reduction. Instead, the p-values are appropriate only for a specific elevation. Cochran's $C$ - test was used to test the assumption of equality of variances. No transformation was used in the few instances of slight $(0.05<p<0.10)$ heteroscedasticity. For seagrass beds in which no significant effect of distance into the bed could be detected by the ANOVAs, we tested each elevation inside the canopy for the presence of a bulk baffling effect of the seagrass bed with a 1-sample, 1-tailed Student's t-test comparing flows at the reference site outside the bed to the set of adjusted flows inside the bed.

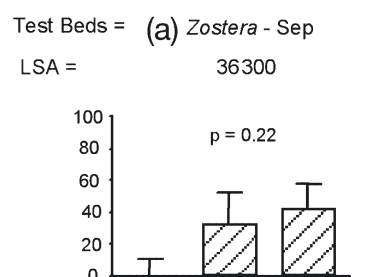

(b) Zostera - May 1993
13100
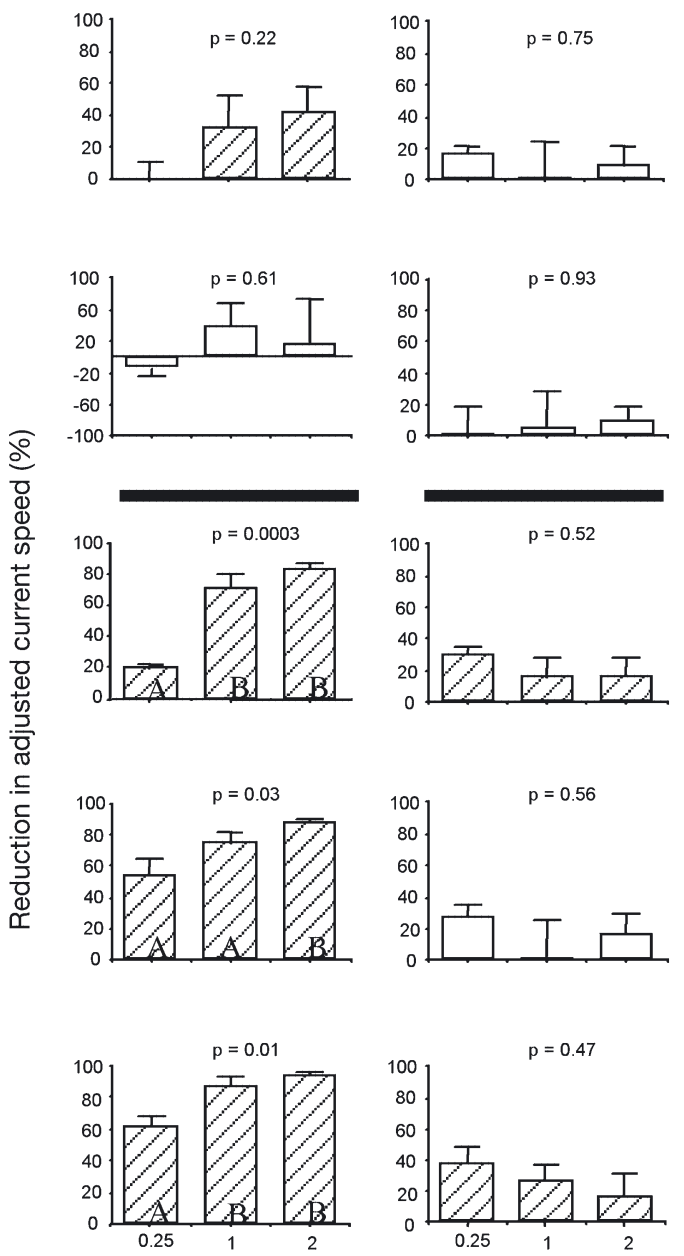
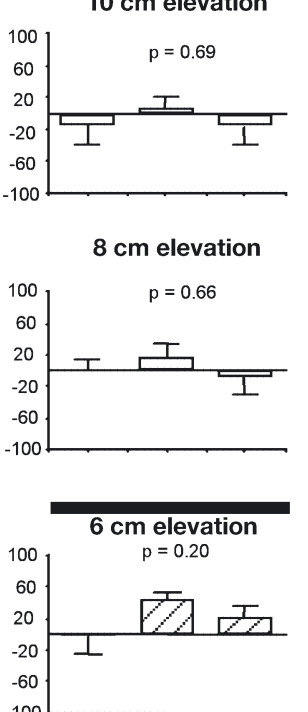

$8 \mathrm{~cm}$ elevation
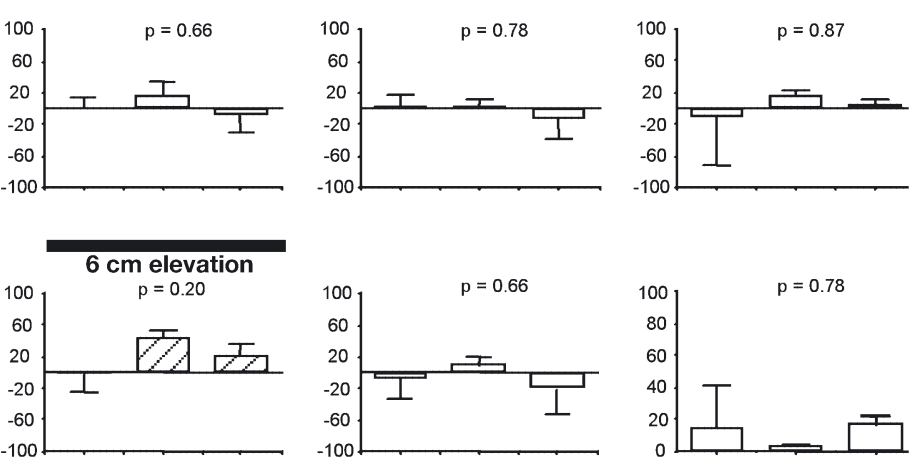

$4 \mathrm{~cm}$ elevation
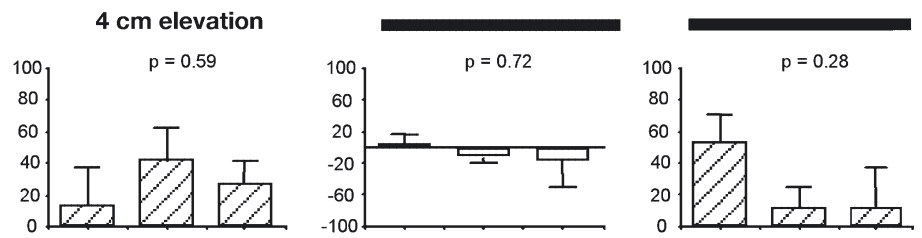

(d) Halodule - Oct 1992
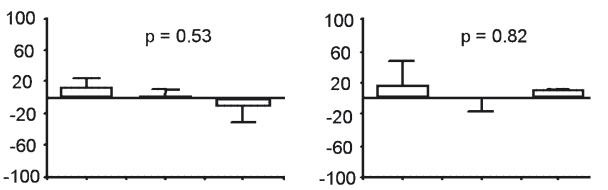

$2 \mathrm{~cm}$ elevation
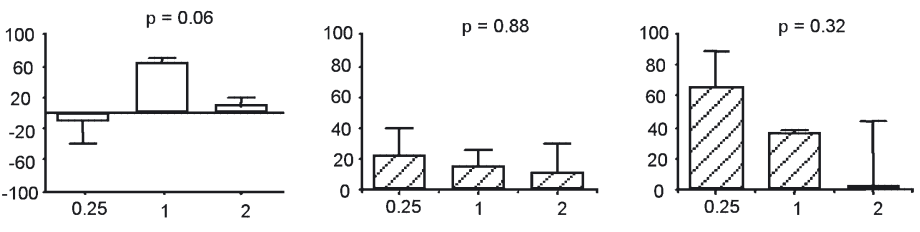

Distance from the edge $(\mathrm{m})$

Fig. 1. Zostera marina and Halodule wrightii. Percentage reduction in adjusted flow velocities as a function of elevation (i.e. height from seafloor) at each of 3 distances into each of 5 seagrass beds compared to reference stations $1 \mathrm{~m}$ in front of beds. Adjustment was made for bathymetric changes between the reference site outside the bed and the measurement sites within the bed (see 'Methods'). Data represent mean flow $(+1 \mathrm{SE})$ from 3 replicate transects into each bed. Horizontal black bars in each column indicate canpoy top. Characteristics of each bed are given in Table 1. LSA: leaf-surface area $\left(\mathrm{cm}^{2} \mathrm{~m}^{-2}\right.$ of bottom) (see Table 1). p-values are results of 1-factor ANOVA for each elevation separately, comparing proportionate reductions in adjusted flows among the 3 distances into the bed. Bars sharing same letter were not significantly different (SNK tests; $\alpha=0.05$ ); hatching of set of bars indicates that flow reduction inside bed was significant at $\alpha=0.05$ (1-tailed Student's $t$-test comparing average difference between each adjusted mean flow inside bed and its paired reference flow to an expected null hypothesis value of zero) 


\section{RESULTS}

\section{Field study}

Velocity profiles in September 1992 for the eelgrass Zostera marina bed that possessed high shoot density $\left(3410 \mathrm{~m}^{-2}\right)$ and relatively long blades (average of $14 \mathrm{~cm}$ for longest leaf in 5 shoots) exhibited a statistically significant $(p<0.05)$ effect of distance into the bed at the 3 lowest elevations, i.e. all those below the approx. $7 \mathrm{~cm}$ high canopy (Fig. 1a). At both 2 and $4 \mathrm{~cm}$, adjusted flow-velocity was reduced by about $60 \%$ at $0.25 \mathrm{~m}$ into the bed compared to velocities $1 \mathrm{~m}$ before the bed. At $6 \mathrm{~cm}$, flow reduction was only about $20 \%$ at $0.25 \mathrm{~m}$, reflecting the likelihood that this sampling location was in the shear zone between the above-canopy and insidecanopy flow regimes. The elevation-integrated reduction in adjusted flow-velocities at 1 and $2 \mathrm{~m}$ distances into the seagrass bed was about $85 \%$ inside the canopy. For each of the elevations $(2,4$, and $6 \mathrm{~cm})$, StudentNewman-Keuls (SNK) tests detected no further reduction in flow velocities from the $1 \mathrm{~m}$ to $2 \mathrm{~m}$ positions inside the bed, but significant differences did exist between the 0.25 and $2 \mathrm{~m}$ positions. At the $8 \mathrm{~cm}$ elevation, a $t$-test comparing the adjusted mean flows at all distances within the bed to the reference flows upstream of the bed indicated no significant flow reduction, but the analogous $t$-test on the adjusted flows for $10 \mathrm{~cm}$ did detect significant flow reduction (Fig. 1a).

This same eelgrass bed was resampled in May 1993, after storms had reduced shoot density to $16 \%$ of the previous level, while the average length of the longest blade per shoot had increased (17 vs $14 \mathrm{~cm}$ : Table 1 ), revealing that this sparsely vegetated bed now had a much reduced impact on near-bed flows (Fig. 1b). No significant effect of distance into the bed was detectable by ANOVA at any elevation. Student's $t$ tests comparing adjusted mean flow across all distances within the bed to the reference flow in front of the bed did reveal a significant reduction in flow within the bed at 2 of the 3 elevations ( 2 and $6 \mathrm{~cm}$ ) inside the approximately $7 \mathrm{~cm}$ high canopy but not at the third elevation $(4 \mathrm{~cm})$. The magnitude of reduction in adjusted mean flow at these 2 elevations was about 30 and $20 \%$, respectively. At $4 \mathrm{~cm}$ elevation, an estimated baffling effect of about $20 \%$ was not statistically detectable. Averaged across all 3 elevations inside the canopy, flow-velocity was reduced by $23 \%$ for the 2 distances ( 1 and $2 \mathrm{~m}$ ) away from the edge. Freestream flows during times of profiling (Table 1) were higher during this spring sampling than in the previous fall ( 14 vs $\left.9 \mathrm{~cm} \mathrm{~s}^{-1}\right)$.

Sampling in the predominantly shoalgrass Halodule wrightii bed in October 1994, where shoot density $\left(3540 \mathrm{~m}^{-2}\right)$ was equal to that of the high-density eelgrass bed but where average length of the longest blade per shoot was slightly less (12 vs $14 \mathrm{~cm}$ ), revealed some flow reduction but with less evident effects of distance into the bed (Fig. 1c). The canopy was again about $7 \mathrm{~cm}$ high. Distance into the bed had no detectable effect on adjusted mean flow at any elevation, except perhaps at $2 \mathrm{~cm}$, where the significance was marginal $(\mathrm{p}=0.06)$. SNK tests among pairs of distances at this $2 \mathrm{~cm}$ elevation indicated that this borderline distance-effect was a con-

Table 1. Zostera marina and Halodule wrightii. Characteristics of the 5 seagrass beds used in field study. Values are averages $(+1 \mathrm{SE})$ of measurements taken at the location of each velocity profile $(\mathrm{N}=9)$. Grass characteristics (shoot density and length of longest blade per shoot) did not vary significantly with distance from the edge of seagrass bed (1-way ANOVAs: $\mathrm{p}=0.30$ to 0.90$)$. Leaf-surface areas estimated for each seagrass bed from average blade width, maximal length, and shoot density determined from grass cores. Vegetation density computed as leaf-surface area per unit area of bottom divided by canopy height. Freestream current velocities measured $10 \mathrm{~cm}$ off the bottom outside seagrass beds $1 \mathrm{~m}$ from bed edge. Water depths measured simultaneously inside and outside seagrass beds at locations where velocity profiles were measured. Estimated flowestablishment zone computed using Eq. (9) assuming that a canopy-drag coefficient $C_{e}=0.1$

\begin{tabular}{|c|c|c|c|c|c|}
\hline \multirow[t]{3}{*}{ Parameter } & \multirow{2}{*}{\multicolumn{2}{|c|}{ Zostera marina }} & \multicolumn{3}{|c|}{-Dominant species } \\
\hline & & & $-H$ & odule wrigh & \\
\hline & Sep 1992 & May 1993 & Oct 1994 & Oct 1992 & May 1993 \\
\hline H. wrightii density (no. shoots $\mathrm{m}^{-2}$ ) & 756 (318) & 0 & $2600(332)$ & $3670(637)$ & $2200(385)$ \\
\hline Z. marina density (no. shoots $\mathrm{m}^{-2}$ ) & $2650(223)$ & $544(80)$ & $942(146)$ & $80(53)$ & $27(27)$ \\
\hline Total shoot density (no. shoots $\mathrm{m}^{-2}$ ) & $3410(225)$ & $544(80)$ & $3540(332)$ & $3740(610)$ & $2230(371)$ \\
\hline Maximal blade length $(\mathrm{cm})$ & $13.9(0.9)$ & $17.2(1.8)$ & $12.4(1.0)$ & $8.2(0.7)$ & $7.4(1.0)$ \\
\hline Leaf surface area (LSA) $\left(\mathrm{cm}^{2} \mathrm{~m}^{-2}\right.$ bottom) & 36300 & 13100 & 22400 & 11300 & 5400 \\
\hline Canopy height, $h(\mathrm{~cm})$ & 7 & 7 & 7 & 5 & 5 \\
\hline Vegetation density, a $\left(\mathrm{m}^{2} \mathrm{~m}^{-3}\right.$ water $)$ & 52 & 19 & 32 & 23 & 11 \\
\hline Free-stream velocity, $U_{\mathrm{o}}\left(\mathrm{m} \mathrm{s}^{-1}\right)$ & $0.09(0.01)$ & $0.14(0.01)$ & $0.05(0.01)$ & $0.13(0.01)$ & $0.06(0.01)$ \\
\hline Water depth over grass bed, $H(\mathrm{~cm})$ & $68.3(3.0)$ & $40.4(3.4)$ & $87.3(3.0)$ & $49.3(2.7)$ & $38.9(3.8)$ \\
\hline Water depth over sand flat $(\mathrm{cm})$ & $84.4(2.8)$ & $45.0(3.3)$ & $87.7(3.2)$ & $56.9(2.7)$ & $43.8(3.9)$ \\
\hline Estimated width of flow-establishment zone, $x_{\text {est }}(\mathrm{m})$ & 0.70 & 1.5 & 1.1 & 1.3 & 2.3 \\
\hline
\end{tabular}


sequence of baffling increasing significantly from the $0.25 \mathrm{~m}$ distance to the $1 \mathrm{~m}$ position in the bed. Although no effect of distance from the edge could be detected at any other elevation, an analogous enhancement of flowattenuation between the 0.25 and $1 \mathrm{~m}$ positions is suggested at the 4 and $6 \mathrm{~cm}$ elevations also (Fig. 1c). Student's $t$-tests revealed that, averaged across all distances, flow-baffling by the seagrass bed was significant only for the 4 and $6 \mathrm{~cm}$ elevations. The estimated average elevation-integrated reduction in flow velocity inside the canopy across the 1 and $2 \mathrm{~m}$ distances away from the edge was $42 \%$. Although we have characterized this bed as predominantly shoalgrass, eelgrass comprised $26 \%$ of the shoots (Table 1). Free-stream flow-speeds outside this bed during the period of measurement were around $5 \mathrm{~cm} \mathrm{~s}^{-1}$, i.e. so low and so close to the detection level of the current meter that resolution of baffling effects was difficult.

In the October 1992 sampling of a nearly monospecific shoalgrass bed (Table 1), seagrass density was again at the same high level of 3740 shoots $\mathrm{m}^{-2}$, but the average length of the longest blade per shoot was reduced to only $8 \mathrm{~cm}$ and effects of the seagrass were evident in the adjusted current-velocity profiles for only 1 elevation inside the canopy (Fig. 1d). ANOVAs revealed no significant effect of distance into the bed for any elevation, and no suggestion of pattern. The $t$ tests revealed only 1 significant baffling effect of the seagrass bed on adjusted mean flows, at $2 \mathrm{~cm}$ elevation. The elevation-integrated average reduction in flow inside the canopy at the 1 and $2 \mathrm{~m}$ distances away from the edge was $17 \%$ (Fig. 1d). Free-stream flowvelocity at the time of profiling this bed was relatively high, at $13 \mathrm{~cm} \mathrm{~s}^{-1}$ (Table 1). Canopy elevation at the time of sampling was about $5 \mathrm{~cm}$.

Sampling in May 1993 of the shoalgrass bed in which both average shoot density $\left(2200 \mathrm{~m}^{-2}\right)$ and average length of the longest blades $(7.4 \mathrm{~cm})$ were low, also revealed no detectable effect of distance on flow reduction inside the bed at any elevation (Fig. 1e). Student's $t$-tests revealed that baffling by the entire bed averaged across all distances was detectable at the 2 lowest elevations (Fig. 1e). Integrated over the 2 and $4 \mathrm{~cm}$ elevations (the only elevations falling within the $5 \mathrm{~cm}$ high canopy), the average reduction in adjusted mean flow for the 1 and $2 \mathrm{~m}$ distances away from the edge was $19 \%$ (Fig. 1e). During the time of profiling, the free-stream flowvelocity at this site was a relatively low $6 \mathrm{~cm} \mathrm{~s}^{-1}$ (Table 1).

\section{Model verification}

We tested our model of flow-attenuation against data from a detailed laboratory flume study of flow through seagrass conducted by Gambi et al. (1990), as well as with our own field data. The high scatter in our field data led us first to use the more carefully controlled flume data in which the flow variations due to 5 seagrass canopy densities and 3 ambient flow-speeds were systematically documented. For each ambient flow-speed, Gambi et al. (1990; their Table 4B) presented ratios of the inside-canopy flow reduction for different canopy densities. We can modify our Eq. (5) to a similar form:

$$
U_{\mathrm{c} 1} / U_{\mathrm{c} 2} \approx U_{\mathrm{o} 1} / U_{\mathrm{o} 2}\left[\left(C_{\mathrm{d}} / H a C_{\mathrm{e}}\right)_{1} /\left(C_{\mathrm{d}} / H a C_{\mathrm{e}}\right)_{2}\right]^{1 / 2}
$$

where Subscripts 1 and 2 refer to different canopy densities. Assuming that total water depth, upstream bottom-drag coefficient and canopy-drag coefficient are not functions of vegetation density, Eq. (10) can be simplified to:

$$
U_{\mathrm{c} 1} / U_{\mathrm{c} 2} \approx U_{\mathrm{o} 1} / U_{\mathrm{o} 2}\left[a_{2} / a_{1}\right]^{1 / 2}
$$

The form of Eq. (11) is particularly attractive since it enables confirmation of our modeling approach without direct knowledge or calibration of a canopy-drag coefficient value. While the canopy-drag coefficient is expected to depend on the physical characteristics of the plants (e.g. plant size, shape, epiphytic growth), the water properties that affect its density and viscosity (salinity, temperature), the assumption of its independence from vegetation density is consistent with other studies of flow through canopies (Abdelrhman 2003). Gambi et al. (1990) presented flow-reduction ratios only for constant upstream velocities (i.e. $U_{\mathrm{c} 1} / U_{\mathrm{c} 2} \approx 1$ ) and using hand-placed seagrass canopies for which the shoot surface areas and numbers of blades per shoot were approximately constant for all canopy densities. In this case, Eq. (11) can be simplified to:

$$
U_{\mathrm{c} 1} / U_{\mathrm{c} 2} \approx\left[S_{2} / S_{1}\right]^{1 / 2}
$$

where $S$ is the shoot density (number of shoots/area). Qualitatively, several investigators have noted that flow speed inside a canopy is inversely related to shoot density (Eckman 1983, 1987, Leonard \& Luther 1995). Eq. (12) provides a theoretical basis for this observation and a predicted quantitative form of the relationship.

For each of the 3 ambient (upstream) flow speeds, we recast Table 4B of Gambi et al. (1990) into a form (present Table 2) that allows direct comparison with Eq. (12). A least-squares linear regression (Fig. 2) of $\ln \left[U_{\mathrm{c} 1} / U_{\mathrm{c} 2}\right]$ against $\ln \left[S_{2} / S_{1}\right]$ reveals a statistically significant relationship $\left(\mathrm{R}^{2}=0.59 ; \mathrm{p}<0.01\right)$. The slope of this regression $(0.5)$ and its intercept $(-0.04)$ match the predicted values of 0.5 and 0 very closely, and provide strong support for our simplified model. Explanations for the scatter in Fig. 2 include: (1) Gambi et al. (1990) included the entire water column in their calculations and therefore incorporated some of the high-shear 
region near the top of the canopy, to which our model does not apply; (2) their canopy densities may not have been entirely uniform either horizontally in space or vertically in the water column; (3) their canopy did not occupy the full width of the flume, so flow within the canopy may have been influenced by flow around the sides of the canopy; (4) their upstream flow and drag values may not have been constant for runs with different canopy densities (e.g. see variations in friction velocity in Gambi et al. 1990; their Table 2).

Our field data revealed statistically significant reductions in ramp-adjusted flow-speeds beneath the canopies for 10 of the 13 tests in the 5 seagrass beds that were examined (Fig. 1). This response is consistent with the qualitative prediction of our model and with previous demonstrations of flow-baffling by seagrass both in the field and in laboratory flumes (e.g. Scoffin 1970, Fonseca et al. 1982, Peterson et al. 1984,

Table 2. Reanalysis of data in Table 4B of Gambi et. al. (1990) from flume study of inside-canopy flow modifications caused by eelgrass canopies of different densities. Data represent ratio of fluxes $\left(U_{\mathrm{c} 1} / U_{\mathrm{c} 2}\right)$ under canopy at different shoot densities $\left(S_{1}, S_{2}\right)$ for 3 different ambient flow speeds

\begin{tabular}{|c|c|c|c|}
\hline$S_{1}$ & $S_{2}$ & $S_{2} / S_{1}$ & $U_{\mathrm{c} 1} / U_{\mathrm{c} 2}$ \\
\hline \multicolumn{4}{|c|}{$5 \mathrm{~cm} \mathrm{~s}^{-1}$ free-stream flow speed } \\
\hline 600 & 400 & 0.67 & 0.848 \\
\hline 800 & 400 & 0.50 & 0.716 \\
\hline 1000 & 400 & 0.40 & 0.542 \\
\hline 1200 & 400 & 0.33 & 0.607 \\
\hline 800 & 600 & 0.75 & 0.845 \\
\hline 1000 & 600 & 0.60 & 0.639 \\
\hline 1200 & 600 & 0.50 & 0.716 \\
\hline 1000 & 800 & 0.80 & 0.757 \\
\hline 1200 & 800 & 0.67 & 0.848 \\
\hline 1200 & 1000 & 0.83 & 0.893 \\
\hline \multicolumn{4}{|c|}{$10 \mathrm{~cm} \mathrm{~s}^{-1}$ free-stream flow speed } \\
\hline 600 & 400 & 0.67 & 0.998 \\
\hline 800 & 400 & 0.50 & 0.699 \\
\hline 1000 & 400 & 0.40 & 0.690 \\
\hline 1200 & 400 & 0.33 & 0.611 \\
\hline 800 & 600 & 0.75 & 0.736 \\
\hline 1000 & 600 & 0.60 & 0.726 \\
\hline 1200 & 600 & 0.50 & 0.643 \\
\hline 1000 & 800 & 0.80 & 0.987 \\
\hline 1200 & 800 & 0.67 & 0.874 \\
\hline 1200 & 1000 & 0.83 & 0.886 \\
\hline \multicolumn{4}{|c|}{$20 \mathrm{~cm} \mathrm{~s}^{-1}$ free-stream flow speed } \\
\hline 600 & 400 & 0.67 & 0.866 \\
\hline 800 & 400 & 0.50 & 0.666 \\
\hline 1000 & 400 & 0.40 & 0.634 \\
\hline 1200 & 400 & 0.33 & 0.422 \\
\hline 800 & 600 & 0.75 & 0.855 \\
\hline 1000 & 600 & 0.60 & 0.813 \\
\hline 1200 & 600 & 0.50 & 0.634 \\
\hline 1000 & 800 & 0.80 & 0.951 \\
\hline 1200 & 800 & 0.67 & 0.634 \\
\hline 1200 & 1000 & 0.83 & 0.666 \\
\hline
\end{tabular}

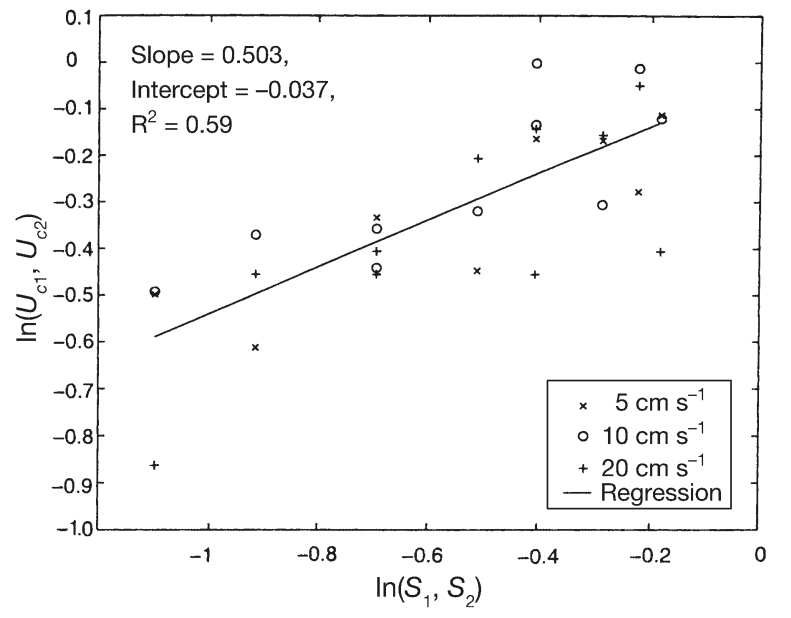

Fig. 2. Plot of ratio of fluxes $\left(U_{\mathrm{c} 1} / U_{\mathrm{c} 2}\right)$ inside seagrass canopy as a function of ratio of shoot densities $\left(S_{1}, S_{2}\right)$ in pairs of eel grass beds in flume studies by Gambi et al. (1990). Data are given in Table 2 . Line is least-squares regression fit $(p<0.01)$

Worcester 1995, Schutten \& Davy 2000, Verduin \& Backhaus 2000). Our measurements also confirm a second, more quantitative prediction of the model: the proportionate reduction in inside-canopy flow velocity increases with increasing vegetation density. The Zostera marina bed tested in September 1992 had substantially higher vegetation density than any other bed tested and, accordingly, had by far the greatest effect on flow beneath its canopy (Fig. 1).

We used the field data to conduct a quantitative assessment of our model following a procedure similar to that applied to analyze the flume data. For each bed, we first computed the mean (ramp-adjusted) insidecanopy flow beyond the outer flow-establishment zone (excluding the $0.25 \mathrm{~m}$ distance and averaging percentage reductions for the 1 and $2 \mathrm{~m}$ distances at all elevations below the canopy: Fig.1). The resulting mean inside-canopy velocity, corresponding ambient velocity, and vegetation density for each bed were used to test Eq. (11). A least-squares linear regression of $\ln \left[\left(U_{c 1} / U_{o 1}\right) /\left(U_{c 2} / U_{o 2}\right]\right.$ vs $\ln \left[a_{2} / a_{1}\right]$ for all possible pairs of combinations of the 5 beds revealed a noisy and non-significant relationship, with a slope of 0.34 and an intercept of 0.98 . When compared to the values predicted from Eq. (11) of 0.5 and 0 , our field results therefore provide only qualitative, not quantitative, corroboration of our model. This is not surprising, since in all but 3 cases we compared beds of different seagrass composition and thus probably different canopy-drag coefficients.

Our field data also help characterize decelerating flow patterns at the leading edge of the seagrass bed that occur before the characteristic inside-canopy flow regime is fully established. In laboratory flume studies, 
Fonseca et al. (1982) and Gambi et al. (1990) each demonstrated that the magnitude of flow reduction increased with distance into the bed, a pattern that we confirmed in the field for the 2 seagrass beds with greatest vegetation density (Fig. 1a,c). The Zostera marina bed with the highest vegetation density was the only bed for which we were able to quantify and describe the 2-dimensional flow reduction pattern at the leading edge of a bed (Fig. 1a). At the $0.25 \mathrm{~m}$ distance, flow reduction was about $60 \%$ at the 2 and $4 \mathrm{~cm}$ elevations (both statistically significant), but at the $6 \mathrm{~cm}$ elevation inside the $7 \mathrm{~cm}$ canopy, the observed flow-depression was only a non-significant $20 \%$. As flow reached 1 and $2 \mathrm{~m}$ into the bed, the reduction caused by baffling did not differ much among elevations. Such depth-dependent penetration of flow into the bed is consistent with the view that seagrass beds slow water-flows in part by diverting them over the obstruction, implying that flow-velocity is more rapidly reduced near the seafloor than higher in the water column in this flow-establishment zone.

Our model provides a quantitative prediction of the width of this flow-establishment zone as a function of vegetation density (Eq. 9). Unfortunately, insufficient information was provided by Gambi et al. (1990) to allow verification of this aspect of our model using their data. We were also not able to develop a method for assessing the functional form of our model independent of the canopy-drag coefficient. We did, however, estimate $x_{\text {est }}$ for the seagrass beds studied in the field, using the values in Table 1 and assuming $C_{\mathrm{d}}=0.0025$ (a standard value used in hydrodynamic modeling) and $C_{\mathrm{e}}=0.1$ (obtained by tuning). The resulting $x_{\text {est }}$ values are presented in Table 1 . This value of $C_{\mathrm{e}}$ can be compared to values of $C_{\mathrm{e}}>0.05$ for water flow through salt-marsh grass (Burke \& Stolzenbach 1983), $C_{\mathrm{e}} \approx 0.5$ for air flow through corn plants (den Hartog \& Shaw 1975), $C_{\mathrm{e}}=0.7$ for water flow through seagrass beds (Abdelrhman 2003) and $C_{\mathrm{e}} \approx 2.5$ for air flowing through bean plants (Thom 1971). Estimates of $x_{\text {est }}$ across our 5 test beds range from 70 to $230 \mathrm{~cm}$, depending primarily on vegetation density (Table 1). These model predictions are consistent in magnitude with the width of the flow-reduction zone observed in the 2 most densely vegetated test beds $(\sim 1 \mathrm{~m}$ : Table 1$)$ and with the lack of a clear establishment of insidecanopy flows at the $1 \mathrm{~m}$ distance in the less densely vegetated beds (Fig. 1), suggesting that Eq. (9) may prove useful for predicting the extent of edge zones in differing seagrass beds. Interestingly, Fonseca et al. (1982) estimated that the zone over which no detectable flow reduction occurs depends on freestream flow velocity, whereas our model predicts a relationship with vegetation density, not flow velocity. Subsequent testing under more controlled conditions could profitably decide between these alternative predictions.

\section{DISCUSSION}

Despite much recent progress in developing more refined and quantitative models of how interactions between emergent plants and near-bottom water flow alter the flow regime (e.g. Worcester 1995, Koch 1996, Kutija \& Hong 1996, Koch \& Gust 1999, Verduin \& Backhaus 2000, Abdelrhman 2003), many aspects of this process of flow modification remain unexplored. The most comprehensive of the previous models, that of Verduin \& Backhaus (2000), is configured to utilize detailed information on spatially varying canopy structure and coefficients. Its complexity allows determination of many of the flow details within the canopy, but does not provide quantitative parametric insight into the effects of ambient velocity and vegetation density on canopy-affected flow. Abdelrhman (2003) provided a simpler model that depends on a canopy-drag coefficient and an additional calibration coefficient, both of which are not well known for seagrass beds. Our new model assumes simple momentum balances and provides quantitative predictions of the impact of seagrass structure on bulk water flow inside and above the canopy and the width of the flow-establishment zone at the leading edge of the bed where flow deceleration occurs prior to the establishment of the within-canopy profile. Our model's dependence on a canopy-drag coefficient alone provides the attractive feature of simplicity for many sedimentological and biological applications. Its close functional agreement with the extensive flume data of Gambi et al. (1990) provides evidence that the model may be a useful tool for predicting bulk-flow effects of seagrass canopies. While quantitatively unverified by any experimental data, our model for determining the width of the edge zone does explain differences observed in mensurative tests comparing different seagrass beds in the field, and provides a quantitative hypothesis predicting the width of this region for guidance in future experimental work. Previous modeling efforts have not addressed this flow-establishment zone.

Both the magnitude of flow-attenuation and also the width of the active deceleration zone are likely to have important sedimentological and benthic biological implications, as sediments and biological particles such as organic particulates and spores and larvae undergo increasing deposition (Ginsburg \& Lowestam 1958, Peterson et al. 1984, Eckman 1987). Anthropogenic fragmentation of seagrass meadows (Thayer et al. 1975) implies the creation of larger proportions of canopy-edge habitat, thereby posing the question of 
how biological functions will be affected. By specifying the length scales of an important physical function of the seagrass-edge habitat, our model permits firstorder hydrodynamic discrimination between the area of the edge versus the core seagrass habitats for different scenarios of patch size, free-stream flow, and vegetation density. Once inside-canopy flow is fully established, our model provides a simple method to predict the magnitude of attenuation in vertically integrated inside-canopy flow. The choice between our model and that of Abdelrhman (2003) may depend largely on whether the relevant application requires information on intensity of flow-attenuation and the width of the edge zone or on the vertical flow variation within the canopy. Both models require data on the contributions of epiphytes to slow flow, beyond the effects of the grass alone; these data could be introduced via an appropriate canopy-drag coefficient.

The very close fit between quantitative model predictions of the magnitude of inside-canopy flow-reduction and the flume data, together with the cruder confirmation of the magnitude of baffling and width of the flowestablishment zone in the field, indicate that our simple model has a utility and predictive value. Application of the model can advance our understanding of how structural features of seagrass beds combine to affect the scale, pattern, and intensity of flow reduction. This simplified method, enabling quantitative predictions of bulk-flow baffling, may lead to improved appreciation of habitat functions by linking habitat structure to the transport and deposition of larvae (e.g. Eckman 1983, Peterson 1986, Butman 1987) and seeds (Blanchette et al. 1999), to the ability of larvae to express habitat selection (Butman et al. 1988, Weissburg \& Zimmer-Faust 1993), to the erosion of surface-dwelling benthic animals (Fegley 1987, Wilson 1990), to biogeochemical transfers (Koch 1994, Nepf \& Koch 1999), and to growth of invertebrates tied to particulate fluxes (Irlandi \& Peterson 1991). Refinement of this model by relating parameter values to properties of seagrass elements is an obvious next step. The inclusion of structural differences among alternative seagrass types to account for varying flexibility of components could yield important new insights into why different seagrasses may have different values as habitats.

While considerable study has been devoted to understanding atmospheric flow through vegetated canopies, including forests and agricultural crops, comparable quantitative studies of marine flow in seagrass canopies have not yet been conducted. For instance, canopy-drag coefficient values are not well known for seagrasses. The atmospheric community has developed partially constitutive expressions for specifying drag-coefficients in terms of the drag on single elements and shelter coefficients; we are unaware of any similar progress for seagrass. Many forest and vegetated canopies maintain a reasonably constant form under typical atmospheric conditions; however, seagrasses bend considerably in aquatic flows. While we presume that this behavior causes the plants to become more streamlined and hence reduces drag as flow velocity increases (Koehl 1986), we have no information on the resulting drag properties of the canopy. Thus, future modeling efforts would benefit considerably from systematic studies of seagrass dragparameters, for example as functions of seagrass morphology and flow velocity.

Acknowledgements. We thank J. E. Byers, L. Kellogg, W. L. Falls, and M. Nakaoka for help in the field, M. S. Fonseca and E. A. Irlandi for advice, and M. A. Abdelrhman and 3 anonymous referees for valuable guidance. Financial support was provided by grants from the Biological Oceanography Program of the National Science Foundation (NSF) and from the National Oceanographic and Atmospheric Administration (NOAA) NERRS Program.

\section{LITERATURE CITED}

Abdelrhman MA (2003) Effect of eelgrass Zostera marina canopies on flow and transport. Mar Ecol Prog Ser 248: $67-83$

Ackerman JD, Okubo A (1993) Reduced mixing in a marine macrophyte canopy. Funct Ecol 7:305-309

Anderson SM, Charters AC (1982) A fluid dynamics study of seawater flow through Gelidium nudifrons. Limnol Oceanogr 27:399-412

Bell SS, Hall MO, Robbins BD (1995) Toward a landscape approach in seagrass beds: using macroalgal accumulation to address questions of scale. Oecologia 104:163-168

Blanchette CA, Worcester SE, Reed D, Holbrook SJ (1999) Algal morphology, flow, and spatially variable recruitment of surfgrass Phyllospadix torreyi. Mar Ecol Prog Ser 184: 119-128

Burke RW, Stolzenbach KD (1983) Free surface flow through salt marsh grass. MIT-Sea Grant Report MITSG 83-16. Massachusetts Institute of Technology Sea Grant Program, Cambridge, MA

Butman CA (1987) Larval settlement of soft-sediment invertebrates: the spatial scales of pattern explained by active habitat selection and the emerging role of hydrodynamical processes. Oceanogr Mar Biol Annu Rev 25:113-165

Butman CA, Grassle JP, Webb CM (1988) Substrate choices made by marine larvae settling in still water and in a flume flow. Nature 333:771-773

den Hartog G, Shaw RH (1975) A field study of atmospheric exchange processes within a vegetative canopy. In: deVries DA, Afgan NH (eds) Heat and mass transfer in the biosphere. John Wiley \& Sons, New York

Eckman JE (1983) Hydrodynamic processes affecting benthic recruitment. Limnol Oceanogr 28:241-257

Eckman JE (1987) The role of hydrodynamics in recruitment, growth, and survival of Argopecten irradians (L.) and Anomia simplex (D'Orbigny) within eelgrass meadows. J Exp Mar Biol Ecol 106:165-191

Fegley SR (1987) Experimental variation of near-bottom current speeds and its effect on depth distribution of sand- 
living meiofauna. Mar Biol 95:183-192

Fonseca MS, Bell SS (1998) Influence of physical setting on seagrass landscapes near Beaufort, North Carolina, USA. Mar Ecol Prog Ser 171:109-121

Fonseca MS, Fisher JS, Zieman JC, Thayer GW (1982) Influence of the seagrass, Zostera marina, on current flow. Estuar Coast Shelf Sci 15:351-364

Fonseca MS, Zieman JC, Thayer GW, Fisher JS (1983) The role of current velocity in structuring eelgrass (Zostera marina L.) meadows. Estuar Coast Shelf Sci 17:367-380

Fréchette M, Butman CA, Geyer WR (1989) The importance of boundary-layer flow in supplying phytoplankton to the benthic suspension feeder, Mytilus edulis L. Limnol Oceanogr 34:19-36

Gambi MC, Nowell ARM, Jumars PA (1990) Flume observations on flow dynamics in Zostera marina (eelgrass) beds. Mar Ecol Prog Ser 61:159-169

Ginsburg RN, Lowenstam HA (1958) The influence of marine bottom communities on the depositional environment of the sediments. J Geol 66:310-318

Grizzle RE, Short FT, Newell CR, Hoven H, Kindblom L (1996) Hydrodynamically induced synchronous waving of seagrasses: 'monami' and its possible effects on larval mussel settlement. J Exp Mar Biol Ecol 206:165-177

Hovel KA, Fonseca MS, Myer DL, Kenworthy WJ, Whitfield PE (2002) Effects of seagrass landscape structure, structural complexity and hydrodynamic regime on macrofaunal densities in North Carolina seagrass beds. Mar Ecol Prog Ser 243:11-24

Irlandi EA, Crawford MK (1997) Habitat linkages: the effect of intertidal saltmarshes and adjacent subtidal habitats on abundance, movement and growth of an estuarine fish. Oecologia 110:222-230

Irlandi EA, Peterson CH (1991) Modification of animal habitat by large plants: mechanisms by which seagrasses influence clam growth. Oecologia 87:307-318

Jackson GA, Winant CD (1983) Effect of a kelp forest on coastal currents. Contin Shelf Res 2:75-85

Koch EW (1994) Hydrodynamics, diffusion-boundary layers and photosynthesis of the seagrasses Thalassia testudinum and Cymodocea nodosa. Mar Biol 118:767-776

Koch EW (1996) Hydrodynamics of a shallow Thalassia testudinum bed in Florida, USA. In: Kuo J, Phillips RC, Walker DI, Kirkman H (eds) Seagrass biology. Proceedings of an International Workshop, Rottnest Island, Jan 25-29, 1996. University of Western Australia, Perth, p 105-110

Koch EW, Gust G (1999) Water flow in tide- and wavedominated beds of the seagrass Thalassia testudinum. Mar Ecol Prog Ser 184:63-72

Koehl MAR (1986) Form and function of macroalgae in moving water. In: Givinish TJ (ed) On the economy of plant form and function. Cambridge University Press, Cambridge, p 291-314

Kutija V, Hong HTM (1996) A numerical model for assessing the additional resistance to flow introduced by flexible vegetation. J Hydraulic Res 34:99-114

Leonard LA, Luther ME (1995) Flow hydrodynamics in tidal marsh canopies. Limnol Oceanogr 40:1474-1484

Lopez F, Garcia M (1997) Open-channel flow through simulated vegetation: turbulence modeling and sediment

Editorial responsibility: Lisa Levin (Contributing Editor), La Jolla, California, USA transport. Wetlands Research Program Technical Report WRP-CP-10. US Army Corps of Engineers, Waterways Experiment Station, Vicksburg, MS

McRoy CP, McMillan C (1977) Production ecology and physiology of seagrasses. In: McRoy CP, Helfferich C (eds) Seagrass ecosystems: a scientific perspective. Dekker, New York, p 89-122

Muschenheim DK (1987) The dynamics of near-bed seston flux and suspension-feeding benthos. J Mar Res 45:473-496

Nepf HM, Koch EW (1999) Vertical secondary flows in submerged plant-like arrays. Limnol Oceanogr 44:1072-1080

Palmer MA (1988) Epibenthic predators and marine meiofauna: separating predation, disturbance, and hydrodynamic effects. Ecology 69:1251-1259

Peterson CH (1986) Enhancement of Mercenaria mercenaria densities in seagrass beds: is pattern fixed during settlement season or altered by subsequent differential survival? Limnol Oceanogr 31:200-205

Peterson CH, Summerson HC, Duncan PB (1984) The influence of seagrass cover on population structure and individual growth rate of the suspension-feeding bivalve, Mercenaria mercenaria. J Mar Res 42:123-138

Raupach MR, Thom AS (1981) Turbulence in and above plant canopies. Annu Rev Fluid Mech 13:97-129

Raupach, MR, Antonia RA, Rajagopalan S (1991) Rough-wall turbulent boundary layers. Appl Mech Rev 44:1-25

Reid RO, Whitaker RE (1976) Wind-driven flow of water influenced by a canopy. J Waterways Harbours Coast Eng Divi Am Soc Civ Eng 102(WW1):61-77

Ruckelshaus MH, Hays C (1998) Conservation of species in the sea. In: Fiedler P, Kareiva P (eds) Conservation biology for the coming decade. Chapman \& Hall, New York, p 112-156

Schutten J, Davy AJ (2000) Predicting the hydraulic forces on submerged macrophytes from current velocity, biomass and morphology. Oecologia 123:445-452

Scoffin TP (1970) The trapping and binding of subtidal carbonate sediments by marine vegetation in Bimini Lagoon, Bahamas. J Sediment Petrol 40:249-273

Thayer GW (ed) (1992) Restoring the nation's marine environment. Maryland Seagrant Program, College Park, MD

Thayer GW, Wolfe DA, Williams RB (1975) The impact of man on seagrass sytems. Am Sci 63:289-296

Thom AS (1971) Momentum absorption by vegetation. Q J R Meteorol Soc 97:414-428

Verduin JJ, Backhaus JO (2000) Dynamics of plant-flow interactions for the seagrass Amphibolus antarctica: field observations and model simulations. Estuar Coast Shelf Sci 50:185-204

Vogel S (1994) Life in moving fluids: the physical biology of flow, 2nd edn. Princeton University Press, Princeton, NJ

Weissburg MJ, Zimmer-Faust RK (1993) Life and death in moving fluids: hydrodynamic effects on chemosensorymediated prediction. Ecology 74:1428-1443

Wilson FS (1990) Temporal and spatial patterns of settlement: a field study of molluscs in Bogue Sound, North Carolina. J Exp Mar Biol Ecol 139:201-220

Worcester SE (1995) Effects of eelgrass beds on advection and turbulent mixing in low current and low shoot density environments. Mar Ecol Prog Ser 126:223-232

Submitted: February 5, 2003; Accepted: October 21, 2003

Proofs received from author(s): February 23, 2004 